\title{
Estimation of daily intake of lycopene, antioxidant contents and activities from tomatoes, watermelons, and their processed products in Korea
}

\author{
Hyunjeong Park ${ }^{1}$, Young-Jun $\mathrm{Kim}^{2^{*}}$ and Youngjae Shin ${ }^{1^{*}}$ (i)
}

\begin{abstract}
Tomatoes, watermelons, and processed tomato products contain abundant antioxidant compounds, including lycopene. In spite of the interest in the role of lycopene, little is known about the contribution of tomatoes and tomato products commonly consumed in Korea to the intake of lycopene. In this study, the daily per capita intake values of lycopene and antioxidant compounds and activities of tomatoes, watermelons, and their processed products in Korea were estimated. The daily per capita intake values of lycopene from raw tomatoes, watermelons, tomato ketchup, and tomato juice were measured to be $1.07,0.54,0.26$, and $0.08 \mathrm{mg} / \mathrm{capita} /$ day, respectively. The average lycopene intake of male and female were 1.98 and $1.92 \mathrm{mg} /$ capita/day, respectively. The daily per capita intake value of total phenolics was highest in raw tomatoes $(7.21 \mathrm{mg} / \mathrm{capita} /$ day), followed by watermelons $(1.72 \mathrm{mg} /$ capita/day), tomato ketchup $(1.41 \mathrm{mg} / \mathrm{capita} /$ day), and tomato juice $(0.80 \mathrm{mg} / \mathrm{capita} /$ day). The daily per capita intake value of total antioxidant activities also showed a similar pattern to total phenolic results. The overall daily per capita intake of antioxidant content and activities was affected by both the daily per capita intake of each product and the levels of antioxidant content and activities of each product. The daily per capita intake of these products in Korea is currently considerably low, compared to the U.S. and Europe. Thus, an adequate consumption of lycopene-rich products is recommended.
\end{abstract}

Keywords: Antioxidant, Daily intake per capita, Lycopene, Tomato, Watermelon

\section{Introduction}

As nutrition improved at the national level, the problems related to nutrient deficiency decreased; however, the western dietary pattern has caused nutritional imbalance to emerge, along with various chronic diseases, such as hypertension, cancer, and diabetes [1]. According to the 2018 report of the World Health Organization (WHO), cancer is the cause of death for one in six individuals worldwide, with one of the five factors of

\footnotetext{
*Correspondence: kimjy@seoultech.ac.kr; ys234@dankook.ac.kr ${ }^{1}$ Department of Food Engineering, Dankook University, Cheonan, Chungnam 31116, Republic of Korea

2 Department of Food Science and Technology, Seoul National University of Science and Technology, Seoul 01811, Republic of Korea
}

carcinogenesis being low intake of fruits and vegetables [2]. Further, numerous epidemiological investigations have proved the effects of fruits and vegetables on preventing chronic diseases $[3,4]$.

Tomato (Solanum lycopersicum L.) is an annual or perennial plant of the Solanaceae family. It is one of the widely consumed vegetables that is available both raw and in the form of various types of processed products, such as ketchup, juice, and sauce [5, 6]. Korean tomato production increased from 276,663 tons in 2000 to 374,677 tons in 2017 , indicating an annual positive increase rate [7]. Tomato is a vegetable that is rich in lycopene and accounts for $80 \%$ of the carotenoids in ripe tomatoes $[4,6]$. Watermelons, apricots, and guavas also contain lycopene. However, more than $85 \%$ of our dietary 
lycopene comes from tomato fruit and tomato-based products $[8,9]$. The lycopene in tomatoes showed a steep increase during the maturation process [10].

Watermelon (Citrullus vulgaris) is a representative summer fruit and a dicotyledoneae that belongs to the Cucurbitaceae family of the order Cucurbitales. The current major watermelon producers are the U.S., Turkey, South Korea, and China [11]. In South Korea, watermelon production in 2017 was approximately 295,422 tons [7]. Lycopene accounts for approximately $70-90 \%$ of carotenoids in mesocarp cell chromoplasts of watermelons [12]. The lycopene in watermelons is responsible for the red pulp, and it acts as the main phytochemical compound that effectively reduces oxidative stress [13].

Lycopene is one of the 600 or more carotenoids that are found in nature. In the past, the correlation between carotenoids and human health was limited to compounds such as, $\alpha$-carotene and $\beta$-carotene, which contain the pro-vitamin A form. However, other carotenoids have known as key phytochemical compounds, and lycopene was especially found to cause the most prominent effect on human health [14]. Lycopene is a natural fat-soluble pigment that is synthesized by plants and microorganisms, but not by animals. Structurally, it is an acyclic carotenoid with a long sequence of 11 conjugated double bonds in all-trans forms, and approximately 72 geometrical isomers have been reported to exist [15]. In addition, unlike other carotenoids, the $\beta$-ionone ring structure is absent in lycopene, and thus pro-vitamin A activity is known to be low $[11,14]$.

As of recent, no studies have estimated the Korean daily per capita intake of antioxidant compounds and activities, such as those of lycopene, that are present in tomatoes, watermelons, and their processed products. Thus, the present study aimed to analyze the antioxidant compounds and activities with special emphasis on lycopene from tomatoes, watermelons, and their processed products. The study also estimated the daily per capita consumption of each food product using the food intake data of the Korea National Health and Nutrition Examination Survey (KNHANES) that was conducted by the Korea Disease Control Division in 2017 [16]. Then, based on the findings, the daily per capita intake values of lycopene and antioxidant compounds and activities of tomatoes, watermelons, and their processed products in Korea were estimated.

\section{Materials and methods Materials}

The samples were purchased from local fruit markets and hypermarkets in the city of Cheonan, South Korea. A total of 35 different types of samples were used, which include 4 types of common tomatoes, 4 types of cherry tomatoes, 15 types of watermelons, 8 types of tomato ketchup, and 4 types of tomato juice. Each product was labeled with a number to not disclose the name of the manufacturer. Common tomatoes, cherry tomatoes, and watermelons were rapidly frozen with $-196{ }^{\circ} \mathrm{C}$ liquid nitrogen and stored in $-25{ }^{\circ} \mathrm{C}$ freezer for subsequent extraction to analyze antioxidant compounds and activities. In addition, the samples of tomato ketchup and tomato juice were stored according to the condition that was indicated in the product label for subsequent analysis.

\section{Extraction to measure antioxidant compounds and activities}

A total of $300 \mathrm{~mL}$ of $80 \%$ methanol was mixed with $30 \mathrm{~g}$ of samples of freeze-stored common tomatoes, cherry tomatoes, and watermelons. Afterwards, using a blender (JB 3060, Braun Co., Kronberg, Germany), homogenization was implemented for three minutes twice and for two minutes once. The supernatant was then filtered using Whatman \# 2 filter paper and concentrated using a rotary evaporator (N-1000, Eyela, Tokyo, Japan). It was then stored at $-25^{\circ} \mathrm{C}$ for subsequent measurements of lycopene content, antioxidant compounds, and activities.

\section{Total flavonoid analysis}

The total flavonoid content of samples was measured using the colorimetric assay method [17, 18]. Briefly, $0.3 \mathrm{~mL}$ of $5 \% \mathrm{NaNO}_{2}$ was added to a mixture of deionized water and $1 \mathrm{~mL}$ aliquot of the diluted sample. After vortexing, the mixture rested at room temperature for $5 \mathrm{~min}$. Next, $0.3 \mathrm{~mL}$ of $10 \% \mathrm{AlCl}_{3}$ was added, and after vortexing, the mixture was placed at room temperature for $6 \mathrm{~min}$. Finally, $2 \mathrm{~mL}$ of $1 \mathrm{~N} \mathrm{NaOH}$ and $2.4 \mathrm{~mL}$ of distilled water were added to adjust the volume to $10 \mathrm{~mL}$. The absorbance was measured at $510 \mathrm{~nm}$ using a spectrophotometer (Optizen POP, Mecasys, Daejeon, Korea), and the total flavonoid content was expressed as mg rutin equivalents (RE) $\mathrm{kg} /$ fresh weight (FW).

\section{Total phenolic analysis}

The total phenolic content of samples was measured using the Folin-Ciocalteu colorimetric assay method [17, 18]. After adding $0.2 \mathrm{~mL}$ of the Folin-Ciocalteu phenol reagent to $0.2 \mathrm{~mL}$ aliquot of the diluted sample that was mixed with deionized water, the mixture was vortexed and made to rest at room temperature for $6 \mathrm{~min}$. Next, $2 \mathrm{~mL}$ of $7 \% \mathrm{NaCO}_{3}$ were added, and the mixture was vortexed, and placed at room temperature in a dark place for $90 \mathrm{~min}$. The absorbance was measured at $750 \mathrm{~nm}$ using a spectrophotometer, and the total phenolic content was expressed as mg gallic acid equivalents (GAE)/kg FW. 


\section{Lycopene analysis}

The lycopene content of the samples was measured according to Bicanic's method with some modifications $[19,20]$. For each $1.0 \mathrm{~g}$ of samples, a small amount of deionized water and methanol was added, and the mixture was vortexed after placing Celite powder (No. 545). A glass filter (3G3) was inserted to a glass vessel, and then using an aspirator (AAA71015, Jeio Tech Co. Ltd., Daejeon, Korea), aspiration-filtration was implemented while methanol was simultaneously added until the yellow color of the sample solution turned a transparent color. Next, the glass filter was moved and fixed to another glass vessel, and then aspiration-filtration was implemented while benzene was added until the color of the filtrate turned transparent. The filtrate was then transferred to a $100 \mathrm{~mL}$ flask, and benzene was used as the sample solution after adjusting to a constant volume. The absorbance was measured at $487 \mathrm{~nm}$ using a spectrophotometer, and the lycopene content was expressed as $\mathrm{mg} / \mathrm{kg} \mathrm{FW}$.

\section{DPPH radical scavenging activity analysis}

The DPPH radical scavenging activity was measured using a modified method by Shin [18] and Brand-Williams et al. [21]. Briefly, $2.95 \mathrm{~mL}$ of DPPH solution were added to a mixture of $50 \mu \mathrm{L}$ of the sample and deionized water. Then, the homogenized mixture sat and reacted at room temperature in a dark place for $30 \mathrm{~min}$. The absorbance was measured at $517 \mathrm{~nm}$ using a spectrophotometer, and the measured DPPH radical scavenging activity was expressed as $\mathrm{mg}$ vitamin $\mathrm{C}$ equivalents (VCE) $/ \mathrm{kg}$ FW.

\section{ABTS radical scavenging activity analysis}

The ABTS radical scavenging activity of the extracted samples was measured using a modified method by Floegel et al. [22] and Re et al. [23]. Briefly, $980 \mu \mathrm{L}$ of ABTS solution were added to a mixture of $20 \mu \mathrm{L}$ sample and deionized water. The homogenized mixture was then allowed to react at $37^{\circ} \mathrm{C}$ for $10 \mathrm{~min}$. The absorbance was measured at $734 \mathrm{~nm}$ using a spectrophotometer, and the measured ABTS radical scavenging activity was expressed as mg VCE/kg FW.

\section{Daily intake of tomatoes, watermelons, and their processed products}

The daily intake values of tomatoes, watermelons, and their processed products were estimated using the Korea National Health and Nutrition Examination Survey (KNHANES VII-2) that was conducted by the Korea Center for Disease Control and Prevention in 2017 [16]. The KNHANES consisted of a health survey, an examination survey, and a nutrition survey. The nutrition survey was conducted by visiting the target households, while the survey consisted of a dietary life survey, a food safety survey, a food intake frequency investigation, and a food intake investigation. The food intake investigation examined all foods that were ingested by the subject during the previous day. The investigation was based on individual interviews, using the $24 \mathrm{~h}$ recall method. The investigation object of the 2017 KNHANES VII-2 that was used in this study recruited 10,430 subjects, among who 8,127 participated in at least one of the following three surveys: the health survey, examination survey, and nutrition survey, with an overall $77.9 \%$ participation rate and an $80 \%$ rate for the nutrition survey.

\section{Estimation of daily per capita intake of antioxidant compounds and activities}

To estimate the daily per capita intake of lycopene and the antioxidant compounds and activities of tomatoes, watermelons, and their processed products, the results of the KNHANES and chemical analysis of the measured contents were used. The calculations were based on the following equations:

Daily per capita intake of total flavonoids (mg RE/ person $/$ day) $=\sum \mathrm{C}_{\mathrm{i}} \mathrm{F}_{\mathrm{i}}$

$\mathrm{C}_{\mathrm{i}}$ indicates the daily per capita intake of tomatoes, watermelons, and their processed products based on raw data; $F_{i}$ indicates the total flavonoid content of tomatoes, watermelons, and their processed products.

Daily per capita intake of total phenolics (mg GAE/ person $/$ day $)=\sum C_{\mathrm{i}} \mathrm{P}_{\mathrm{i}}$

$\mathrm{C}_{\mathrm{i}}$ indicates the daily per capita intake of tomatoes, watermelons, and their processed products based on raw data; $P_{i}$ indicates the total phenolic content of tomatoes, watermelons, and their processed products.

Daily per capita intake of lycopene (mg/person/ day) $=\sum \mathrm{C}_{\mathrm{i}} \mathrm{L}_{\mathrm{i}}$

$\mathrm{C}_{\mathrm{i}}$ indicates the daily per capita intake of tomatoes, watermelons, and their processed products based on raw data; $\mathrm{L}_{\mathrm{i}}$ indicates the lycopene content of tomatoes, watermelons, and their processed products.

Daily per capita intake regarding DPPH radical scavenging activity (mg VCE/person/day) $=\sum \mathrm{C}_{\mathrm{i}} \mathrm{D}_{\mathrm{i}}$

$\mathrm{C}_{\mathrm{i}}$ indicates the daily per capita intake of tomatoes, watermelons, and their processed products based on raw data; $\mathrm{D}_{\mathrm{i}}$ indicates the level of DPPH radical scavenging activity of tomatoes, watermelons, and their processed products.

Daily per capita intake regarding ABTS radical scavenging activity ( $\mathrm{mg} \mathrm{VCE} /$ person/day) $=\sum \mathrm{C}_{i} \mathrm{~A}_{i}$

$\mathrm{C}_{\mathrm{i}}$ indicates the daily per capita intake of tomatoes, watermelons, and their processed products based on raw data; $A_{i}$ indicates the level of ABTS radical scavenging 
activity of tomatoes, watermelons, and their processed products.

\section{Statistical analysis}

For statistical analysis, the SPSS 20 program (SPSS Inc., Chicago, IL, USA) was used. For each test group, a oneway analysis of variance (ANOVA) was implemented, and Duncan's multiple range test was used for the significance of each average value $(p<0.05)$.

\section{Results and discussion}

\section{Total flavonoid content}

The total flavonoid content of tomatoes, watermelons, and their processed products, is as presented in Table 1. The total flavonoid content of tomatoes was measured to be between 172.86 and $556.19 \mathrm{mg} \mathrm{RE} / \mathrm{kg} \mathrm{FW}$, while that of watermelons was between 89.52 and $268.57 \mathrm{mg} \mathrm{RE} /$ $\mathrm{kg}$ FW. For tomato ketchup and tomato juice, the range was between 1,570.00 and 2,784.29 $\mathrm{mg} \mathrm{RE} / \mathrm{kg} \mathrm{FW}$, and between 446.67 and $956.67 \mathrm{mg} \mathrm{RE} / \mathrm{kg} \mathrm{FW}$, respectively.

Compared to common tomatoes, the total flavonoid content of cherry tomatoes showed higher levels with significant differences. According to the study by Hallmann [24] on the bioactive compounds in different types of tomatoes, the total flavonoid content of cherry tomatoes was $98.54 \pm 8.22 \mathrm{mg} / 100 \mathrm{~g}$ in dry weight (DW), while that of common tomatoes was $59.20 \pm 7.65 \mathrm{mg} / 100 \mathrm{~g}$ in DW, which agrees with the results of this study. In addition, processed tomato products (ketchup and juice) showed 2-16 times higher flavonoid content compared to raw tomatoes. This is because naringenin, which is a flavanone that is most abundant in tomatoes, increases during such processes as part of heat treatment [25]. Likewise, apple juice has been reported to show approximately a $50 \%$ increase in the flavonoid content following heat treatment at $40-70{ }^{\circ} \mathrm{C}$ [26]. In addition, according to a study by Tlili et al. [12], antioxidant compounds and activities varies based the maturity of watermelons, and the total flavonoid content of red-ripe watermelons was $193.1 \pm 4.8 \mathrm{mg} \mathrm{RE} / \mathrm{kg} \mathrm{FW}$, which is consistent with this study. Not only in the case of watermelons, but also for raw tomatoes and processed tomato products, differences in total flavonoid content were shown according to the cultivar, country of origin, and manufacturer. This may be caused by the fact that each sample and product raw material differ in terms of the cultivar, country of origin, harvest period, and processing [27, 28].

\section{Total phenolic content}

The total phenolic content of the products is as presented in Table 1. The total phenolic content of tomatoes was measured between 267.18 and $775.04 \mathrm{mg}$ GAE $/ \mathrm{kg}$ FW, while that of watermelons was between 133.75 and
$176.83 \mathrm{mg} \mathrm{GAE} / \mathrm{kg}$ FW. For tomato ketchup and tomato juice, the range was between 800.00 and $1,200.00 \mathrm{mg}$ GAE/kg FW, and between 293.25 and $472.75 \mathrm{mg} \mathrm{GAE} / \mathrm{kg}$ FW, respectively.

Tomato ketchup, compared to raw tomatoes, showed approximately 2.2 times higher mean content. According to a study by Gahler et al. [29] as the time of heat treatment increased during the sterilization processing of tomatoes, the total phenolic content increased. Thus, in the case of tomato ketchup, various processing steps, such as heat treatment, have been found to increase the total phenolic content higher than in the case of raw tomatoes. In the case of tomato juice, on the other hand, the content was shown to be lower than that of raw tomatoes. This pattern is believed to be due to the peeling process during the production of tomato juice, whereby the abundant phenolic compounds, such as rutin, rutin apioside, naringenin, and naringenin chalcone in the peel, are reduced [25]. However, according to Klopotek et al. [30], antioxidant compounds and activities of processed strawberry products were lower than those of raw strawberries, as based on the processing. Notably, in the case of strawberry juice after the low-temperature sterilization processing step, the total phenolic content was shown to be $27 \%$ lower than that of raw strawberries. This may be due to the loss of the anthocyanin component in strawberries by the heat that is provided during the sterilization processing step, which lowered the total phenolic content. In addition, according to Nagal et al. [31], the total phenolic content of watermelons was measured to be between 13.05 and $18.08 \mathrm{mg} \mathrm{GAE} / 100 \mathrm{~g}$ FW, which is in accord with the results of this study.

\section{Lycopene content}

The lycopene content of the products is presented in Table 1. The lycopene content of tomatoes was measured to be between 40.19 and $108.06 \mathrm{mg} / \mathrm{kg} \mathrm{FW}$, while that of watermelons was between 24.23 and $69.12 \mathrm{mg} /$ $\mathrm{kg}$ FW. For tomato ketchup, the range was 116.59 and $254.98 \mathrm{mg} / \mathrm{kg} \mathrm{FW}$; for tomato juice, the range was 9.90 and $54.21 \mathrm{mg} / \mathrm{kg} \mathrm{FW}$.

According to Martinez-Valverde et al. [32], the lycopene content of various tomato cultivars in Spain was $18.60-64.98 \mathrm{mg} / \mathrm{kg} \mathrm{FW}$, which is a range that is lower than in this study. In contrast, the lycopene content of tomatoes in Croatia was $1.82-11.19 \mathrm{mg} / 100 \mathrm{~g}$ FW, which is consistent with this study [33]. This may be due to the differences in the cultivar, maturity, and cultivation conditions with influence on the lycopene content of tomatoes. Moreover, for tomato ketchup, the products across different brands showed significant differences. This is believed to be due to the differences in the content of tomato paste in each product, 
Table 1 Levels of antioxidant content and activities of tomato, tomato juice, tomato ketchup, and watermelon

\begin{tabular}{|c|c|c|c|c|c|c|}
\hline \multirow[t]{2}{*}{ Product } & \multirow[t]{2}{*}{ Brands } & \multirow[t]{2}{*}{$\begin{array}{l}\text { Total flavonoids } \\
\text { (mg RE/kg FW) }\end{array}$} & \multirow[t]{2}{*}{$\begin{array}{l}\text { Total phenolics (mg } \\
\text { GAE/kg FW) }\end{array}$} & \multirow[t]{2}{*}{ Lycopene (mg/kg FW) } & \multicolumn{2}{|c|}{$\begin{array}{l}\text { Antioxidant activities (mg VCE/kg } \\
\text { FW) }\end{array}$} \\
\hline & & & & & DPPH & ABTS \\
\hline \multirow[t]{9}{*}{ Tomato } & CT1 & $540.95 \pm 4.10$ & $775.04 \pm 1.28$ & $77.69 \pm 4.57$ & $495.31 \pm 2.86$ & $920.51 \pm 13.78$ \\
\hline & $\mathrm{CT} 2$ & $351.90 \pm 10.52$ & $594.87 \pm 6.54$ & $108.06 \pm 4.37$ & $387.70 \pm 5.71$ & $718.13 \pm 6.55$ \\
\hline & СT3 & $367.14 \pm 3.09$ & $617.78 \pm 0.48$ & $101.72 \pm 1.18$ & $398.38 \pm 4.95$ & $694.98 \pm 8.15$ \\
\hline & CT4 & $556.19 \pm 9.43$ & $664.27 \pm 1.28$ & $59.10 \pm 2.94$ & $419.75 \pm 8.83$ & $824.61 \pm 10.62$ \\
\hline & TM1 & $202.80 \pm 2.94$ & $281.71 \pm 0.61$ & $64.69 \pm 2.81$ & $159.35 \pm 4.49$ & $287.97 \pm 3.27$ \\
\hline & TM2 & $172.86 \pm 2.02$ & $340.68 \pm 1.47$ & $68.84 \pm 5.67$ & $215.68 \pm 1.94$ & $355.76 \pm 7.02$ \\
\hline & TM3 & $187.62 \pm 2.43$ & $299.49 \pm 1.26$ & $40.19 \pm 1.58$ & $180.88 \pm 1.30$ & $300.20 \pm 8.57$ \\
\hline & TM4 & $220.95 \pm 1.78$ & $267.18 \pm 0.73$ & $48.41 \pm 2.41$ & $135.08 \pm 1.30$ & $278.04 \pm 3.74$ \\
\hline & Average & $325.00 \pm 146.08^{c}$ & $480.13 \pm 190.34^{b}$ & $71.09 \pm 22.65^{b}$ & $299.02 \pm 131.48^{\mathrm{a}}$ & $547.52 \pm 251.31^{\mathrm{a}}$ \\
\hline \multirow[t]{5}{*}{ Tomato juice } & J1 & $956.67 \pm 57.93$ & $439.50 \pm 6.96$ & $48.33 \pm 1.24$ & $31.19 \pm 2.04$ & $233.39 \pm 6.10$ \\
\hline & $J 2$ & $776.67 \pm 41.67$ & $472.75 \pm 9.21$ & $45.99 \pm 2.30$ & $147.46 \pm 2.32$ & $313.62 \pm 4.40$ \\
\hline & $J 3$ & $446.67 \pm 37.69$ & $293.25 \pm 1.84$ & $9.90 \pm 1.78$ & $59.55 \pm 2.32$ & $159.03 \pm 1.84$ \\
\hline & J4 & $781.90 \pm 42.01$ & $442.25 \pm 6.83$ & $54.21 \pm 9.25$ & $187.79 \pm 4.46$ & $352.44 \pm 3.48$ \\
\hline & Average & $740.48 \pm 19.00^{b}$ & $411.94 \pm 7.01^{b}$ & $40.49 \pm 1.84^{c}$ & $106.50 \pm 6.36^{c}$ & $264.62 \pm 7.47^{b}$ \\
\hline \multirow[t]{9}{*}{ Tomato ketchup } & K1 & $2545.71 \pm 188.41$ & $1120.00 \pm 28.94$ & $206.14 \pm 2.80$ & $224.02 \pm 18.57$ & $633.06 \pm 15.12$ \\
\hline & K2 & $2340.00 \pm 123.02$ & $1035.00 \pm 31.82$ & $204.11 \pm 1.63$ & $213.63 \pm 5.83$ & $579.24 \pm 12.84$ \\
\hline & K3 & $2588.57 \pm 60.71$ & $1058.33 \pm 17.83$ & $199.29 \pm 4.55$ & $204.49 \pm 4.46$ & $560.76 \pm 2.03$ \\
\hline & K4 & $2494.29 \pm 61.31$ & $1062.50 \pm 26.06$ & $205.83 \pm 1.92$ & $208.90 \pm 2.67$ & $605.88 \pm 4.28$ \\
\hline & K5 & $1564.29 \pm 51.55$ & $801.67 \pm 22.58$ & $116.59 \pm 0.58$ & $126.35 \pm 4.52$ & $423.23 \pm 6.83$ \\
\hline & K6 & $1570.00 \pm 107.30$ & $800.00 \pm 5.40$ & $116.98 \pm 0.39$ & $134.54 \pm 7.81$ & $418.88 \pm 2.77$ \\
\hline & K7 & $2737.14 \pm 99.98$ & $1199.17 \pm 24.61$ & $254.98 \pm 1.05$ & $180.86 \pm 2.48$ & $592.83 \pm 4.28$ \\
\hline & K8 & $2784.29 \pm 100.59$ & $1200.00 \pm 19.69$ & $246.14 \pm 0.43$ & $184.64 \pm 8.95$ & $602.61 \pm 11.48$ \\
\hline & Average & $2328.04 \pm 47.02^{\mathrm{a}}$ & $1034.58 \pm 14.86^{\mathrm{a}}$ & $193.76 \pm 4.85^{\mathrm{a}}$ & $184.68 \pm 3.51^{b}$ & $552.06 \pm 7.86^{\mathrm{a}}$ \\
\hline \multirow[t]{16}{*}{ Watermelon } & W1 & $114.76 \pm 2.69$ & $140.08 \pm 1.53$ & $40.79 \pm 2.50$ & $49.96 \pm 0.63$ & $88.73 \pm 0.72$ \\
\hline & W2 & $160.95 \pm 3.37$ & $133.75 \pm 0.74$ & $69.12 \pm 3.86$ & $38.46 \pm 0.36$ & $87.06 \pm 0.98$ \\
\hline & W3 & $130.00 \pm 2.33$ & $164.83 \pm 0.12$ & $24.23 \pm 2.18$ & $45.54 \pm 0.36$ & $91.18 \pm 0.42$ \\
\hline & W4 & $178.10 \pm 1.35$ & $155.57 \pm 1.03$ & $60.07 \pm 0.73$ & $48.19 \pm 1.30$ & $105.46 \pm 0.27$ \\
\hline & W5 & $172.86 \pm 1.17$ & $146.08 \pm 0.66$ & $61.56 \pm 1.46$ & $38.02 \pm 1.08$ & $88.95 \pm 0.69$ \\
\hline & W6 & $189.52 \pm 8.75$ & $150.50 \pm 1.95$ & $35.81 \pm 1.36$ & $44.76 \pm 0.22$ & $86.39 \pm 1.19$ \\
\hline & W7 & $113.81 \pm 4.10$ & $136.00 \pm 1.34$ & $47.08 \pm 0.35$ & $41.62 \pm 0.39$ & $84.83 \pm 0.16$ \\
\hline & W8 & $104.76 \pm 4.42$ & $141.58 \pm 0.31$ & $50.95 \pm 0.91$ & $30.14 \pm 0.22$ & $83.27 \pm 0.32$ \\
\hline & W9 & $92.38 \pm 1.78$ & $143.08 \pm 0.51$ & $47.36 \pm 1.91$ & $38.47 \pm 0.44$ & $85.94 \pm 0.79$ \\
\hline & W10 & $89.52 \pm 2.43$ & $139.17 \pm 0.82$ & $48.77 \pm 1.55$ & $32.18 \pm 0.39$ & $76.57 \pm 0.16$ \\
\hline & W11 & $109.05 \pm 4.86$ & $135.75 \pm 0.71$ & $47.28 \pm 2.31$ & $16.93 \pm 0.80$ & $58.28 \pm 0.27$ \\
\hline & W12 & $134.76 \pm 1.78$ & $158.17 \pm 1.05$ & $47.51 \pm 0.29$ & $49.64 \pm 1.93$ & $86.17 \pm 0.63$ \\
\hline & W13 & $156.67 \pm 3.75$ & $153.75 \pm 1.59$ & $49.71 \pm 1.07$ & $37.06 \pm 0.22$ & $75.46 \pm 0.16$ \\
\hline & W14 & $268.57 \pm 2.02$ & $169.08 \pm 3.95$ & $32.60 \pm 0.93$ & $36.86 \pm 0.39$ & $94.75 \pm 0.47$ \\
\hline & W15 & $140.95 \pm 0.67$ & $176.83 \pm 3.68$ & $43.48 \pm 3.55$ & $61.28 \pm 0.45$ & $116.61 \pm 1.03$ \\
\hline & Average & $143.78 \pm 45.22^{d}$ & $149.62 \pm 12.84^{c}$ & $47.09 \pm 11.14^{c}$ & $40.61 \pm 9.96^{d}$ & $87.31 \pm 12.63^{c}$ \\
\hline
\end{tabular}

Results are mean values \pm standard deviation from three measurements $(n=3)$ of each sample; means in the same column with superscript with different letters $(a, b$, $c$, and d) are significantly different at $\mathrm{p}<0.05$. (RE rutin equivalent, GAE gallic acid equivalent, VCE vitamin $C$ equivalent, $F W$ fresh weight)

which influences the lycopene content. Thus, tomato ketchup with high tomato paste content showed significantly higher lycopene content. On the other hand, the difference in lycopene content between raw tomatoes and processed tomato products is considered due to processing, such as sterilization [32]. In the case of tomatoes, lycopene synthesis was found to be suppressed by temperatures that are above $37{ }^{\circ} \mathrm{C}$ during the day throughout cultivation, whereas the temperature did not affect watermelons [34]. Thus, lycopene 
content in watermelons has been found to be influenced by maturity, soil fertility, and light intensity.

\section{DPPH radical scavenging activity}

The DPPH radical scavenging activity values of the products are presented in Table 1. The DPPH radical scavenging activity of tomatoes was measured be within the range of 135.08 and $495.31 \mathrm{mg} \mathrm{VCE} / \mathrm{kg} \mathrm{FW}$, while that of watermelons was measured to be within the range of 16.93 and $61.28 \mathrm{mg} \mathrm{VCE} / \mathrm{kg} \mathrm{FW}$. For tomato ketchup, the range was 126.35 and $224.02 \mathrm{mg} \mathrm{VCE} / \mathrm{kg} \mathrm{FW}$; for tomato juice, the range was 31.19 and $187.79 \mathrm{mg} \mathrm{VCE/}$ kg FW. According to Floegel et al. [22], the DPPH radical scavenging activity values of raw tomatoes and tomato juice were 44.2 and $62.6 \mathrm{mg} \mathrm{VCE} / 100 \mathrm{~g}$, respectively. The results of the present study indicate a similar trend for raw tomatoes, whereas a relatively lower level of content was demonstrated by tomato juice. This may be due to differences in tomato paste content in tomato juice, product processing methods, and tomato cultivars.

\section{ABTS radical scavenging activity}

The ABTS radical scavenging activity values of the products are presented in Table 1. The ABTS radical scavenging activity of tomatoes were found to be within the range of 278.04 and $920.51 \mathrm{mg} \mathrm{VCE} / \mathrm{kg} \mathrm{FW}$, while that of watermelons was relatively low and within the range of 58.28 and $116.61 \mathrm{mg} \mathrm{VCE} / \mathrm{kg}$ FW. For tomato ketchup, the range was 418.88 and $633.06 \mathrm{mg} \mathrm{VCE} / \mathrm{kg} \mathrm{FW}$; for tomato juice, the range was 159.03 and $352.44 \mathrm{mg} \mathrm{VCE} / \mathrm{kg} \mathrm{FW}$. Floegel et al. [22] found that the ABTS radical scavenging activity of tomato ketchup was $48.1 \pm 1.2 \mathrm{mg} \mathrm{VCE} / 100 \mathrm{~g}$ FW, while Chun et al. [35] reported the ABTS radical scavenging activity of tomatoes to be $29.44 \pm 1.60 \mathrm{mg}$ $\mathrm{VCE} / 100 \mathrm{~g}$ FW, which all implicate a similar trend to that of this study.

\section{Daily intake of tomatoes, watermelons, and their processed products}

Table 2 presents the data that were obtained from analyzing the 2017 KNHANES VII-2 data regarding the daily per capita intake of the products in Korea [16]. The daily per capita intake of the products, according to gender and age, are presented in Table 3. Analyzing the intake according to gender showed that the daily per capita intake was higher in males than in females in terms of total consumption of watermelons, tomato ketchup, and juice, but not raw tomatoes. The intake of raw tomatoes in women according to age showed a decrease in the order of age: $50 \sim 64>30 \sim 49>65$ or above $>19 \sim 2$ $9>3 \sim 5>6 \sim 11>12 \sim 18>1 \sim 2$. In addition, analyzing the intake according to age showed that the intake of raw tomatoes in male and female who were aged 30 or above was approximately $60.35 \%$ and $64.39 \%$ from total consumption, respectively. The intake of raw tomatoes was relatively lower in male and female who were aged below 30. In contrast, for tomato ketchup, the intake in males and females who were aged below 30 was approximately $81.82 \%$ and $78.79 \%$, respectively. Hence, the group of those who are aged $\geq 30$ has been determined to have preference for raw tomatoes over tomato ketchup or juice. According to a study on the daily intake of tomatoes

Table 2 Daily per capita consumption (g/capita/day) from tomato, processed tomato product, and watermelon according to gender and age on the basis of the analysis of the existing dataset in the Korea Health and Nutrition Examination Survey 2017

\begin{tabular}{|c|c|c|c|c|c|c|c|c|c|c|}
\hline \multirow[t]{2}{*}{ Gender } & \multirow[t]{2}{*}{ Product } & \multicolumn{8}{|c|}{ Age (yr) } & \multirow[t]{2}{*}{ Average } \\
\hline & & $1 \sim 2$ & $3 \sim 5$ & $6 \sim 11$ & $12 \sim 18$ & $19 \sim 29$ & $30 \sim 49$ & $50 \sim 64$ & $\geq 65$ & \\
\hline \multirow[t]{4}{*}{ Male } & Tomato & 4.67 & 5.46 & 7.77 & 4.88 & 11.21 & 14.84 & 18.27 & 18.63 & 13.88 \\
\hline & Tomato juice & 3.48 & $\mathrm{n} / \mathrm{a}$ & 0.74 & 2.39 & 1.55 & 3.53 & $\mathrm{n} / \mathrm{a}$ & 2.12 & 2.30 \\
\hline & Tomato ketchup & 0.36 & 1.05 & 3.09 & 3.51 & 3.33 & 1.78 & 0.58 & 0.16 & 1.72 \\
\hline & Watermelon & 4.95 & 5.26 & 11.24 & 11.78 & 6.38 & 16.79 & 10.42 & 12.36 & 12.01 \\
\hline \multirow[t]{4}{*}{ Female } & Tomato & 0.80 & 8.75 & 7.09 & 6.28 & 9.71 & 18.27 & 23.52 & 17.20 & 16.15 \\
\hline & Tomato juice & $\mathrm{n} / \mathrm{a}$ & $\mathrm{n} / \mathrm{a}$ & 1.85 & $\mathrm{n} / \mathrm{a}$ & $\mathrm{n} / \mathrm{a}$ & 1.72 & 3.12 & $\mathrm{n} / \mathrm{a}$ & 1.57 \\
\hline & Tomato ketchup & 0.47 & 0.34 & 2.04 & 2.45 & 1.35 & 1.20 & 0.44 & 0.15 & 1.00 \\
\hline & Watermelon & 13.02 & 8.79 & 8.89 & 11.75 & 4.51 & 13.32 & 14.77 & 7.24 & 11.00 \\
\hline \multirow[t]{4}{*}{ Average } & Tomato & 2.86 & 7.04 & 7.44 & 5.55 & 10.50 & 16.51 & 20.90 & 17.80 & 15.01 \\
\hline & Tomato juice & 1.85 & $\mathrm{n} / \mathrm{a}$ & 0.94 & 1.25 & 2.65 & 2.65 & 2.41 & $\mathrm{n} / \mathrm{a}$ & 1.94 \\
\hline & Tomato ketchup & 0.41 & 0.95 & 2.58 & 3.01 & 2.40 & 1.50 & 0.51 & 0.15 & 1.36 \\
\hline & Watermelon & 8.73 & 6.95 & 10.09 & 11.77 & 5.50 & 15.10 & 12.60 & 9.41 & 11.51 \\
\hline
\end{tabular}

Various commercial lycopene-rich products in the Korean diet were selected from the existing dataset of the 2017 Korea National Health and Nutrition Examination Survey (KNHANES). $n / a$ data not available 
Table 3 Estimated daily intake of antioxidant contents and activities from tomato, tomato processed product, and watermelon in the Korean diet according to gender

\begin{tabular}{|c|c|c|c|c|c|c|}
\hline \multirow[t]{2}{*}{ Gender } & \multirow[t]{2}{*}{ Brands } & \multirow[t]{2}{*}{$\begin{array}{l}\text { Total flavonoids (mg } \\
\text { RE/capita/day) }\end{array}$} & \multirow[t]{2}{*}{$\begin{array}{l}\text { Total phenolics (mg } \\
\text { GAE/capita/day) }\end{array}$} & \multirow[t]{2}{*}{$\begin{array}{l}\text { Lycopene (mg/ } \\
\text { capita/day) }\end{array}$} & \multicolumn{2}{|c|}{$\begin{array}{l}\text { Antioxidant capacities (mg } \\
\text { VCE/capita/day) }\end{array}$} \\
\hline & & & & & DPPH & ABTS \\
\hline \multirow[t]{5}{*}{ Male } & Tomato & $4.51 \pm 2.03^{\mathrm{a}}$ & $6.67 \pm 2.64^{\mathrm{a}}$ & $0.99 \pm 0.31^{\mathrm{a}}$ & $4.15 \pm 1.82^{\mathrm{a}}$ & $7.60 \pm 3.49^{\mathrm{a}}$ \\
\hline & Tomato juice & $1.71 \pm 0.42^{b}$ & $0.95 \pm 0.16^{b}$ & $0.09 \pm 0.04^{d}$ & $0.25 \pm 0.15^{b}$ & $0.61 \pm 0.17^{b}$ \\
\hline & Tomato ketchup & $4.00 \pm 0.79^{a}$ & $1.78 \pm 0.25^{b}$ & $0.33 \pm 0.08^{c}$ & $0.32 \pm 0.06^{b}$ & $0.95 \pm 0.13^{b}$ \\
\hline & Watermelon & $1.73 \pm 0.54^{b}$ & $1.80 \pm 0.15^{b}$ & $0.57 \pm 0.13^{b}$ & $0.49 \pm 0.12^{b}$ & $1.05 \pm 0.15^{b}$ \\
\hline & Sum & 11.95 & 11.19 & 1.98 & 5.20 & 10.21 \\
\hline \multirow[t]{5}{*}{ Female } & Tomato & $5.25 \pm 2.36^{\mathrm{a}}$ & $7.76 \pm 3.08^{\mathrm{a}}$ & $1.15 \pm 0.36^{\mathrm{a}}$ & $4.83 \pm 2.12^{\mathrm{a}}$ & $8.84 \pm 4.06^{\mathrm{a}}$ \\
\hline & Tomato juice & $1.16 \pm 0.29^{b}$ & $0.65 \pm 0.11^{b}$ & $0.07 \pm 0.03^{c}$ & $0.28 \pm 0.15^{b}$ & $0.42 \pm 0.12^{b}$ \\
\hline & Tomato ketchup & $2.33 \pm 0.46^{b}$ & $1.04 \pm 0.15^{b}$ & $0.20 \pm 0.05^{c}$ & $0.18 \pm 0.03^{b}$ & $0.55 \pm 0.08^{b}$ \\
\hline & Watermelon & $1.58 \pm 0.50^{b}$ & $1.65 \pm 0.14^{b}$ & $0.52 \pm 0.12^{b}$ & $0.45 \pm 0.11^{b}$ & $0.96 \pm 0.14^{b}$ \\
\hline & Sum & 10.32 & 11.08 & 1.92 & 5.73 & 10.77 \\
\hline \multirow[t]{5}{*}{ Average } & Tomato & $4.88 \pm 2.19^{\mathrm{a}}$ & $7.21 \pm 2.86^{\mathrm{a}}$ & $1.07 \pm 0.34^{\mathrm{a}}$ & $4.49 \pm 1.97^{a}$ & $8.22 \pm 3.77^{\mathrm{a}}$ \\
\hline & Tomato juice & $1.44 \pm 0.36^{c}$ & $0.80 \pm 0.14^{b}$ & $0.08 \pm 0.03^{c}$ & $0.21 \pm 0.12^{b}$ & $0.51 \pm 0.14^{b}$ \\
\hline & Tomato ketchup & $3.17 \pm 0.62^{b}$ & $1.41 \pm 0.20^{b}$ & $0.26 \pm 0.07^{c}$ & $0.25 \pm 0.05^{b}$ & $0.75 \pm 0.11^{b}$ \\
\hline & Watermelon & $1.65 \pm 0.52^{c}$ & $1.72 \pm 0.15^{b}$ & $0.54 \pm 0.13^{b}$ & $0.47 \pm 0.11^{b}$ & $1.00 \pm 0.15^{b}$ \\
\hline & Sum & 11.14 & 11.14 & 1.95 & 5.41 & 10.49 \\
\hline
\end{tabular}

Results are mean values \pm standard deviation from three measurements $(n=3)$ of each sample; means in the same column with superscript with different letters $(a$, $b$, $c$, and d) are significantly different at $p<0.05$. (RE rutin equivalent, GAE gallic acid equivalent, VCE vitamin C equivalent)

and tomato ketchup in Greece, the intake was 112.5 and $0.25 \mathrm{~g} /$ day, respectively. The daily per capita intake of raw tomatoes was higher than that of processed tomato products, which is similar to out result [36].

\section{Estimation of daily per capita intake of antioxidant compounds}

The estimation of the daily per capita intake of antioxidant compounds from the products (Table 3), was based on the daily per capita consumption of the products, as calculated using the 2017 KNHANES VII-2 data [16] (Table 2), and the quantitative analysis results of antioxidant compounds in the products (Table 1).

The daily per capita intake values of total flavonoids from tomatoes, watermelons, tomato ketchup and juice were found to be $4.88 \pm 2.19,1.65 \pm 0.52,3.17 \pm 0.62$, and $1.44 \pm 0.36 \mathrm{mg} \mathrm{RE} /$ capita/day, respectively (Table 3 ). For raw tomatoes, the total flavonoid content was lower than that of tomato ketchup (Table 1); however, the daily per capita intake of total flavonoids was significantly higher (Table 3). This was found to be due to the markedly higher daily intake of raw tomatoes than that of tomato ketchup with its contribution to the relatively high daily per capita total flavonoid content. In addition, for tomato ketchup, the daily per capita intake of total flavonoids based on gender was 4.00 and $2.33 \mathrm{mg} \mathrm{RE} /$ capita/day in males and females, respectively (Table 3 ). Although the total flavonoid content of each product was the same, the difference in the intake resulted in the gender differences. Based on the results, the daily per capita total flavonoid intake is likely to be largely influenced by the daily per capita intake, rather than the antioxidant content of each product.

The daily per capita intake values of total phenolics from the products were found to be the highest for raw tomatoes (7.21 $\pm 2.86 \mathrm{mg}$ GAE/capita/day) (Table 3). According to Chun et al. [35], the daily per capita total phenolic intake based on the intake of tomatoes was $24.4 \mathrm{mg} \mathrm{GAE} / \mathrm{capita} /$ day. The total phenolic intake in the U.S. is approximately 3.38 times higher than the results of this study, which suggests that the daily per capita intake of antioxidant compounds is influenced by daily intake.

\section{Estimation of daily per capita intake of lycopene}

The estimated daily intakes of lycopene from the Korean diet according to gender and age are presented in Fig. 1. The daily intake value of lycopene for male and female from the Korean diet was in the order of tomato $>$ watermelon $>$ tomato ketchup $>$ tomato juice (Table 4). Additionally, Table 4 indicates that males and females between the ages of 1-11 consumed high levels of lycopene. It is assumed that this is due to their relatively low body weight compared to the lycopene intake of 1-11 children. Consequently, the average estimated daily intake of lycopene is $0.03 \mathrm{mg} / \mathrm{kg}$ body weight/day for males and females. There was an increasing trend by age, with the 


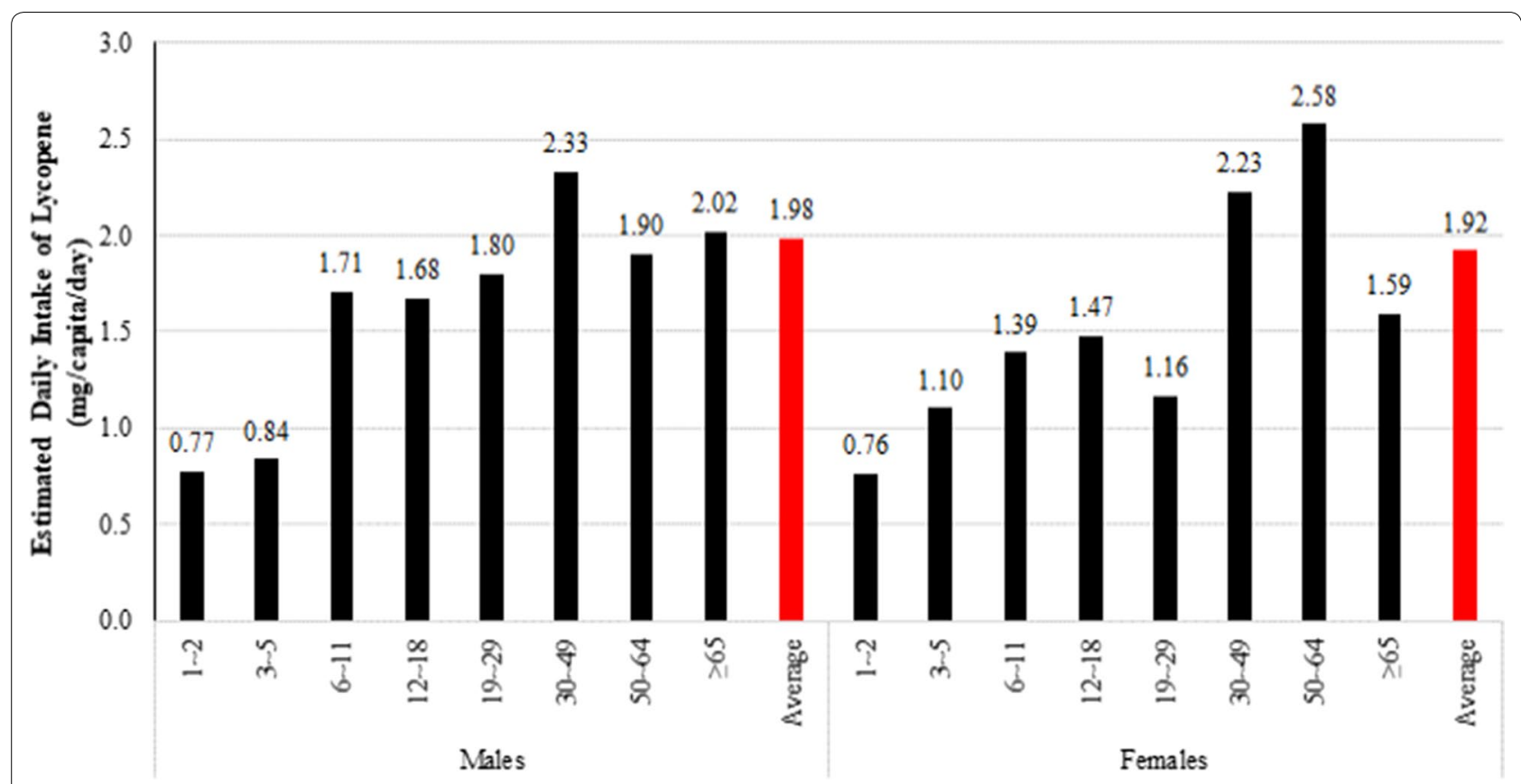

Fig. 1 Total estimated daily intakes of lycopene from tomato, tomato processed product, watermelon in the Korean diet according to gender and age (mg/capita/day)

Table 4 Estimated daily intake of lycopene from tomato, tomato processed product, and watermelon in the Korean diet according to gender and age (mg/capita/day)

\begin{tabular}{|c|c|c|c|c|c|c|}
\hline \multirow[t]{2}{*}{ Gender } & \multirow[t]{2}{*}{ Age } & \multicolumn{4}{|c|}{ Estimated daily intake of lycopene by food stuff (mg/capita/day) } & \multirow{2}{*}{$\begin{array}{l}\text { Estimated total daily intake } \\
\text { of lycopene ( } \mathrm{mg} / \mathrm{kg} \mathrm{bw} / \text { day) }\end{array}$} \\
\hline & & Tomato & Tomato juice & $\begin{array}{l}\text { Tomato } \\
\text { ketchup }\end{array}$ & Watermelon & \\
\hline \multirow[t]{9}{*}{ Males } & $1-2$ & 0.33 & 0.14 & 0.07 & 0.23 & 0.06 \\
\hline & $3-5$ & 0.39 & 0.00 & 0.20 & 0.25 & 0.05 \\
\hline & $6-11$ & 0.55 & 0.03 & 0.60 & 0.53 & 0.05 \\
\hline & $12-18$ & 0.35 & 0.09 & 0.68 & 0.55 & 0.03 \\
\hline & $19-29$ & 0.80 & 0.06 & 0.65 & 0.30 & 0.02 \\
\hline & $30-49$ & 1.05 & 0.14 & 0.34 & 0.79 & 0.03 \\
\hline & $50-64$ & 1.30 & 0.00 & 0.11 & 0.49 & 0.03 \\
\hline & $\geq 65$ & 1.32 & 0.08 & 0.03 & 0.58 & 0.03 \\
\hline & Average & 0.99 & 0.09 & 0.33 & 0.57 & 0.03 \\
\hline \multirow[t]{9}{*}{ Females } & $1-2$ & 0.06 & 0.00 & 0.09 & 0.61 & 0.06 \\
\hline & $3-5$ & 0.62 & 0.00 & 0.07 & 0.41 & 0.06 \\
\hline & $6-11$ & 0.50 & 0.07 & 0.40 & 0.42 & 0.04 \\
\hline & $12-18$ & 0.45 & 0.00 & 0.47 & 0.55 & 0.03 \\
\hline & $19-29$ & 0.69 & 0.00 & 0.26 & 0.21 & 0.02 \\
\hline & $30-49$ & 1.30 & 0.07 & 0.23 & 0.63 & 0.04 \\
\hline & $50-64$ & 1.67 & 0.12 & 0.09 & 0.70 & 0.04 \\
\hline & $\geq 65$ & 1.22 & 0.00 & 0.03 & 0.34 & 0.03 \\
\hline & Average & 1.15 & 0.06 & 0.19 & 0.52 & 0.03 \\
\hline
\end{tabular}


highest intake of $2.33 \mathrm{mg} / \mathrm{capita} /$ day between the age of 30-49 years old for males, then the lycopene intake has decreased at the age of 50. In the same way, females also showed a similar tendency to males, with the highest intake of $2.58 \mathrm{mg} /$ capita/day between the age of 50-64 years old. After 65 years old, the tendency has dropped down. The average lycopene intake of male and female were 1.98 and $1.92 \mathrm{mg} /$ capita/day, respectively (Fig. 1).

Table 5 shows estimated daily intake of lycopene in some countries from representative references [33, 37-46]. However, the comparison with these crude data should be considered carefully because the sample size and methodology differ between studies. When

Table 5 Comparison of estimated daily intake of lycopene in some countries

\begin{tabular}{llll}
\hline Country & Lycopene (mg/capita/day) & Year & References \\
\hline The Netherlands & 1.0 (male), 1.3 (female) & 1998 & {$[37]$} \\
Germany & 1.28 & 1998 & {$[38]$} \\
France & 4.75 & 2001 & {$[39]$} \\
Spain & 1.64 & 2001 & {$[39]$} \\
Republic of Ireland & 4.43 & 2001 & {$[39]$} \\
Netherlands & 4.86 & 2001 & {$[39]$} \\
UK & 1.07 & 2001 & {$[39]$} \\
USA & 10.50 (male), 10.41 (female) & 2001 & {$[40]$} \\
Canada & 6.36 & 2002 & {$[41]$} \\
Hungary & 2.99 (children), 4.26 (adults) & 2003 & {$[42]$} \\
Poland & 1.93 & 2005 & {$[43]$} \\
Australia & 3.81 & 2005 & {$[44]$} \\
Croatia & 4.11 (school children), & 2006 & {$[33]$} \\
& 3.35 (university students) & & \\
Belgium & 1.49 (male), 1.17 (female) & 2013 & {$[45]$} \\
Lithuania & 1.37 & 2015 & {$[46]$} \\
Republic of Korea & 1.98 (male), 1.92 (female) & 2020 & Current study \\
\hline
\end{tabular}

comparing the lycopene intake of the Korean population with that of populations in other countries, it was observed that the intake in Korean is still low comparing to USA (10.41 $10.50 \mathrm{mg} /$ capita/day), Canada $(6.36 \mathrm{mg} /$ capita/day), Netherland (4.86 mg/capita/day), France (4.75 mg/capita/day). The differences between countries may be related to various dietary habits, the quality of the food composition used and the variation of lycopene content within foods.

The average contributive composition percentage (\%) of lycopene from the products according to males and females are presented in Fig. 2. Males consumed 50.01\% lycopene from raw tomato followed by tomato juice, tomato ketchup, and watermelon. Females consumed $59.55 \%$ lycopene from raw tomato, which was higher than that of males. Overall, the total average composition of lycopene was $54.70 \%$ from raw tomato followed by watermelon $(27.81 \%)$, tomato ketchup (13.52\%), and tomato juice (3.97\%). The assessment of the data reveals that the dominant source of lycopene for intake by people is raw tomato.

\section{Estimation of daily per capita intake of antioxidant activities}

The daily per capita intake of antioxidant activities that was estimated based on the DPPH radical scavenging activity showed the following order: tomato $>$ watermelon $>$ tomato ketchup $>$ tomato juice (Table 3). The ABTS radical scavenging activity result also reveals a similar trend. According to Chun et al. [35], the estimated daily per capita intake of antioxidant activities for tomato was $30.3 \mathrm{mg} \mathrm{VCE/capita/day,} \mathrm{which} \mathrm{is} \mathrm{approximately} 3.7$ times higher than the value obtained in this study. This is believed to be due to the difference in the daily per capita tomato intake. In addition, the daily per capita intake values of antioxidant activities by ABTS method in males and females, regarding raw tomato intake, were 7.60 and

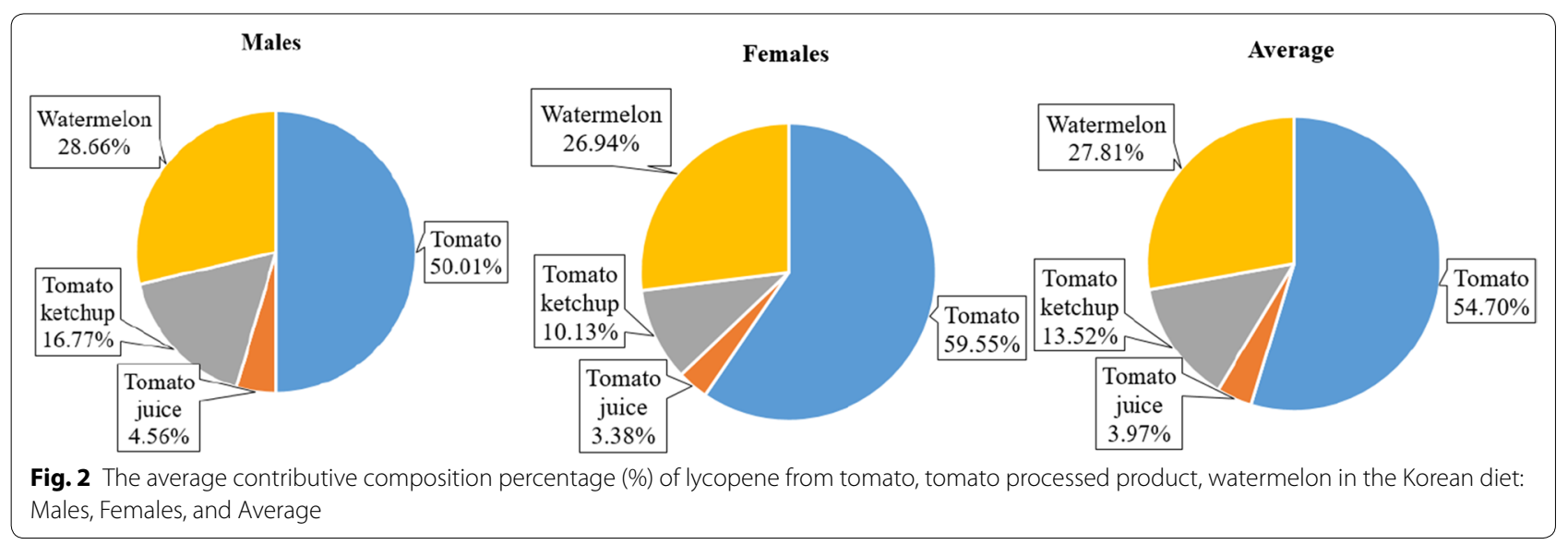


8.84 mg VCE/capita/day, respectively (Table 3). This finding suggests that the higher daily per capita intake of antioxidant activities in women is due to the markedly higher daily raw tomato intake. It has thus been found that the daily per capita intake of antioxidant activities is influenced by the daily intake of each product.

In conclusion, tomatoes, watermelons, and processed tomato products (ketchup and juice) contain an abundance of different antioxidant compounds, including lycopene. For high-level intake of antioxidant compounds and activities from each product, the intake of the product itself should be increased. However, the daily per capita intake of the products in Korea is considerably low, compared to the U.S. and Europe. Thus, an adequate intake of lycopene-rich products is recommended. This study is highly significant in that it involves the estimation of the daily per capita intake of antioxidant compounds including lycopene, and antioxidant activities in Korea, based on the data on the intake of tomatoes, watermelons, and their processed products, as drawn from the quantitative analysis of each product and the KNHANES data.

\section{Acknowledgements}

None.

\section{Authors' contributions}

Conceptualization, YK and YS; methodology, HP, YK, and YS; formal analysis, HP, $Y K$, and $Y S$; writing — original draft preparation, HP; writing — review and editing, YK and YS. All authors read and approved the final manuscript.

\section{Funding}

This research received no external funding.

\section{Availability of data and materials}

The datasets used and analyzed in this study are available from the corresponding authors on reasonable request.

\section{Competing interests}

The authors declare that they have no competing interests.

Received: 30 June 2020 Accepted: 28 August 2020

Published online: 04 September 2020

\section{References}

1. Kwon JH, Shim JE, Park MK (2005) Paik HY (2009) Evaluation of fruit and vegetables intake for prevention of chronic disease in Korean adults aged 30 years and over: Using the third Korea national health and nutrition examination survey (KNHANES III). Korean J Nutr 42(2):146-157

2. WHO (World Health Organization). Cancer fact sheet, 2018. Available online: https://www.who.int/en/news-room/fact-sheets/detail/cancer. Accessed 12 Sept 2018

3. Engelhard YN, Gazer B, Paren E (2006) Natural antioxidants from tomato extract reduce blood pressure in patients with grade-1 hypertension: A double blind, placebo-controlled pilot study. J Am Heart Assoc 151(1):1-6

4. Lenucci MS, Cadinu D, Taurino M, Piro G, Dalessandro G (2006) Antioxidant composition in cherry and high-pigment tomato cultivars. J Agric Food Chem 54(7):2606-2613
5. Frusciante L, Carli P, Ercolano MR, Pemice R, Di-Matteo A, Fogliano V, Pellegrini N (2007) Antioxidant nutritional quality of tomato. Mol Nutr Food Res 51(5):609-617

6. Kamiloglu S, Demirci M, Selen S, Toydemir G, Boyacioglu D, Capanoglu E (2014) Home processing of tomatoes (Solanum lycopersicum): effects on in vitro bioaccessibility of total lycopene, phenolics, flavonoids, and antioxidant capacity. J Sci Food Agric 94(11):2225-2233

7. FAO (Food and Agriculture Organization of the United Nations). FAOSTAT, Production, 2019. Available online: https://www.fao.org/faostat/ en/\#data/QC. Accessed 18 Jan 2019

8. Bohm F, Edge R, Burke M, Truscott TG (2001) Dietary uptake of lycopene protects human cells from singlet oxygen and nitrogen dioxide-ROS components from cigarette smoke. J Photochem Photobiol B: Biol 64(2-3):176-178

9. Nguyen ML, Schwartz SJ (1999) Lycopene: chemical and biological properties. Food Technol 53(2):38-45

10. Singh P, Goyal GK (2016) Dietary lycopene: Its properties and anticarcinogenic effects. Compr Rev Food Sci Food Saf 7(3):255-270

11. Naz A, Butt MS, Pasha I, Nawaz H (2013) Antioxidant indices of watermelon juice and lycopene extract. Pak J Nutr 12:255-260

12. Tlili I, Hdider C, Lenucci MS, Ilahy R, Jebari H, Dalessandro G (2011) Bioactive compounds and antioxidant activities during fruit ripening of watermelon cultivars. J Food Comps Anal 24(7):923-928

13. Hong MY, Hartig N, Kaufman K, Hooshmand S, Figueroa A, Kern M (2015) Watermelon consumption improves inflammation and antioxidant capacity in rats fed an atherogenic diet. Nutr Res 35(3):251-258

14. Ghavipour M, Saedisomeolia A, Djalali M, Sotoudeh G, Eshranghyan MR, Moghada AM, Wood LG (2013) Tomato juice consumption reduces systemic inflammation in overweight and obese females. Br J Nutr 109(11):2031-2035

15. Ferruzzi MG, Nguyen ML, Sander LC, Rock CL, Schwartz SJ (2001) Analysis of lycopene geometrical isomers in biological microsamples by liquid chromatography with coulometric array detection. J Chromatography B 760(2):289-299

16. Korea Health Statistics (2017) Korea National Health and Nutrition Examination Survey (KNHANES VII-2). Korea Center for Disease Control and Prevention; Seoul, Korea, pp 3-25

17. Meyers KJ, Watkins CB, Pritts MP, Liu RH (2003) Antioxidant and antiproliferative activities of strawberries. J Agric Food Chem 51(23):6887-6892

18. Shin Y (2012) Correlation between antioxidant concentrations and activities of Yuja (Citrus junos Sieb ex Tanaka) and other citrus fruits. Food Sci Biotechnol 21(5):1477-1482

19. Bicanic D, Fogliano V, Luterotti S, Swarts J, Piani G, Graziani G (2005) Quantification of lycopene in tomato products: comparing the performances of a newly proposed direct photothermal method and high-performance liquid chromatography. J Sci Food Agric 85(7):1149-1153

20. Bicanic D, Swarts J, Luterotti S, Helander P, Fogliano V, Anese M (2005) Optothermistor as a breakthrough in the quantification of lycopene content of thermally processed tomato-based foods: Verification versus absorption spectrophotometry and high-performance liquid chromatography. J Agric Food Chem 53(9):3295-3299

21. Brand-Williams W, Cuvelier ME, Berset C (1995) Use of a free radical method to evaluate antioxidant activity. LWT-Food Sci Technol 28:25-30

22. Floegel A, Kim DO, Chung SJ, Koo SI, Chun OK (2011) Comparison of ABTS/DPPH assays to measure antioxidant capacity in popular antioxidant-rich US foods. J Food Comp Anal 24(7):1043-1048

23. Re R, Pellegrini N, Proteggente A, Pannala A, Yang M, Rice-Evans C (1999) Antioxidant activity applying an improved ABTS radical cation decolorization assay. Free Radical Biol Med 26(9-10):1231-1237

24. Hallmann E (2012) The influence of organic and conventional cultivation systems on the nutritional value and content of bioactive compounds in selected tomato types. J Sci Food Agric 92(14):2840-2848

25. Kamiloglu S, Boyacioglu D, Capanoglu E (2013) The effect of food processing on bioavailability of tomato antioxidants. J Berry Res 3(2):65-77

26. Gerard KA, Robert JS (2004) Microwave heating of apple mash to improve juice yield and quality. Food Sci Technol 37(5):551-557

27. Tlili I, Hdider C, Lenucci MS, Riadh I, Jebari H, Dalessandro G (2011) Bioactive compounds and antioxidant activities of different watermelon (Citrullus lanatus (Thunb.) Mansfeld) cultivars as affected by fruit sampling area. J Food Comp Anal 24(3):307-314 
28. Lee BH, Kim SY, Cho CH, Chung DK, Chun OK, Kim DO (2011) Estimation of daily per capita intake of total phenolics, total flavonoids, and antioxidant capacities from fruit and vegetable juices in the Korean diet based the Korea National Health and Nutrition Examination survey 2008. Korean J Food Sci Technol 43(4):475-482

29. Gahler S, Otto K, Bohm V (2003) Alterations of vitamin C, total phenolics, and antioxidant capacity as affected by processing tomatoes to different products. J Agric Food Chem 51(27):7962-7968

30. Klopotek Y, Otto K, Böhm V (2005) Processing strawberries to different products alters contents of vitamin c, total phenolics, total anthocyanins, and antioxidant capacity. J Agric Food Chem 53(14):5640-5646

31. Nagal S, Kaur C, Choudhary H, Singh J, Bhushan-Singh B, Singh KN (2012) Lycopene content, antioxidant capacity and colour attributes of selected watermelon (Citrullus lanatus (Thunb.) Mansfeld) cultivars grown in India. Int J Food Sci Nutr 63(8):996-1000

32. Martinez-Valverde I, Periago MJ, Provan G, Chesson A (2002) Phenolic compounds, lycopene and antioxidant activity in commercial varieties of tomato (Lycopersicum esculentum). J Sci Food Agric 82(3):323-330

33. Markovic K, Hruskar M, Vahcic N (2006) Lycopene content of tomato products and their contribution to the lycopene intake of Croatians. Nutr Res 26(11):556-560

34. Perkins-Veazie P, Collins JK, Pair SD, Roberts W (2001) Lycopene content differs among red-fleshed watermelon cultivars. J Sci Food Agric 81(10):983-987

35. Chun OK, Kim DO, Smith N, Schroeder D, Han JT, Lee CY (2005) Daily consumption of phenolics and total antioxidant capacity from fruit and vegetables in the American diet. J Sci Food Agric 85(10):1715-1724

36. Jenab M, Ferrari P, Mazuir M, Tjonneland A, Clavel-chapelon F, Linseisen J, Trichopoulou A, Tumino R, Bueno-de-Mesquita HB, Lund E, Gonzalez CA, JohanssonJ-Key T, Riboli E G (2036S) Variations in lycopene blood levels and tomato consumption across European countries based on the European Prospective Investigation into Cancer and Nutrition(EPIC) study. J Nutr 135(8):2032S-2036S

37. Goldbohm RA, Brants HA, Hulshof KF, Van Den Brandt PA (1998) The contribution of various foods to intake of vitamin $A$ and carotenoids in The Netherlands. Int J Vitam Nutr Res 68(6):378-383
38. Pelz R, Schmidt-Faber B, Heseker H (1998) Carotenoid intake in the German national food consumption survey. Z Ernahrungswiss 37(4):319-327

39. O'Neill ME, Carroll Y, Corridan B, Olmedilla B, Granado F, Blanco I, Van Den Berg H, Hininger I, Rousell AM, Chopra M, Southon S, Thurnham DI (2001) A European carotenoid database to assess carotenoid intakes and its use in a five-country comparative study. British J Nutr 85(4):499-507

40. Porrini M, Riso P (2045S) What are typical lycopene intakes? J Nutr 135(8):2042S-2045S

41. Johnson-Down L, Saudny-Unterberger H, Gray-Donald K (2002) Food habits of Canadians: lutein and lycopene intake in the Canadian population. J Am Diet Assoc 102(7):988-991

42. Lugasi A, Brio L, Hovarie J, Sagi KV, Brandt S, Barna E (2003) Lycopene content of foods and lycopene intake in two groups of the Hungarian population. Nutr Res 23(8):1035-1044

43. Wawrzyniak A, Marciniak A, Rajewska J (2005) Lycopene content of selected foods available on the Polish market and estimation of its intake. Pol J Food Nutr Sci 14(55):195-200

44. McNaughton SA, Marks GC, Gaffney P, Williams G, Green A (2005) Validation of a food-frequency questionnaire assessment of carotenoid and vitamin E intake using weighed food records and plasma biomarkers: the method of triads model. Eur J Clin Nutr 59(2):211-218

45. Vandevijvere S, Cucu T, Vinkx C, Huvaere K, Huybrechts I, Van Loco J (2014) Dietary intake of lycopene by the Belgian adult population. Public Health Nutr 17(2):248-255

46. Mazeikiene A, Jakaitiene A, Karciauskaite D, Kucinskiene ZA, Abaravicius JA, Kaminskas A, Kucinskas V (2015) Dietary lycopene and cardiovascular health in ethnic Lithuanians. Acta Med Litu 22(4):179-187

\section{Publisher's Note}

Springer Nature remains neutral with regard to jurisdictional claims in published maps and institutional affiliations.

\section{Submit your manuscript to a SpringerOpen ${ }^{\circ}$ journal and benefit from:}

- Convenient online submission

- Rigorous peer review

- Open access: articles freely available online

- High visibility within the field

Retaining the copyright to your article

Submit your next manuscript at springeropen.com 